\title{
Verrucous hemangioma and histopathological differential diagnosis with angiokeratoma circumscriptum neviforme*
}

\author{
Kenselyn Oppermann ${ }^{1}$, Ana Letícia Boff², Renan Rangel Bonamigo ${ }^{1,3}$
}

DOI: http:/ / dx.doi.org/10.1590/abd1806-4841.20187259

\begin{abstract}
Verrucous hemangioma is a rare vascular skin disorder with an immune profile similar to vascular neoplasms, but with behavior and evolution of vascular malformations. Its main differential diagnosis is angiokeratoma circumscriptum neviforme, with an almost indistinguishable clinical presentation because both diseases appear as erythematous patches that evolve to violaceous plaques, becoming scaly and even verrucous, most commonly affecting the lower limbs. Histopathology is crucial for the correct diagnosis: while in angiokeratoma the vascular alterations are limited to the papillary dermis, verrucous hemangioma extends deep into the dermis, reaching the subcutaneous tissue.
\end{abstract}

Keywords: Angiokeratoma; Hemangioma; Skin diseases, vascular

\section{CASE REPORT}

Female patient, phototype IV, four years of age, with a history of a reddish irregular patch on the right lumbosacral region that appeared in the first year of life, with rapid and progressive increase, evolving to a hyperkeratotic, verrucous plaque affecting the entire right lower limb, including the plantar region. The lesion was asymptomatic, and there was no report of local trauma or family history.

On detailed physical examination, the lesion showed a linear pattern and morphological differences according to the topo- graphy: it was more erythematous-violaceous on the gluteal region, predominantly scaly on the posterior aspect of the leg, extending to the ipsilateral plantar region, where it appeared as an erythematous patch (Figures 1, 2, and 3). Comparative measurements of the lower limbs showed no discrepancy; X-rays of the lower limbs and electrocardiogram were normal.

Anatomical pathological examination showed mild hyperkeratosis, prominent papillomatosis, and proliferation of small and medium-caliber blood vessels located in the papillary dermis,

\footnotetext{
Received 15 May 2017.

Accepted 04 February 2018.

Work conducted at the Public Health Dermatology Outpatient Clinic of Porto Alegre, Rio Grande do Sul State Health Department, Porto Alegre (RS), Brazil. Financial support: None.

Conflict of interest: None.

Dermatology Department and Public Health Dermatology Outpatient Clinic, Porto Alegre, Rio Grande do Sul State Health Department, Porto Alegre (RS), Brazil.

Pathology Department, Hospital Santa Casa de Misericórdia de Porto Alegre, Porto Alegre (RS), Brazil.

Dermatology Department, Hospital de Clínicas de Porto Alegre, Universidade Federal do Rio Grande do Sul, Porto Alegre (RS), Brazil.
}

\section{MAILING AdDRESS:}

Kenselyn Oppermann

E-mail: kenselyn@gmail.com 


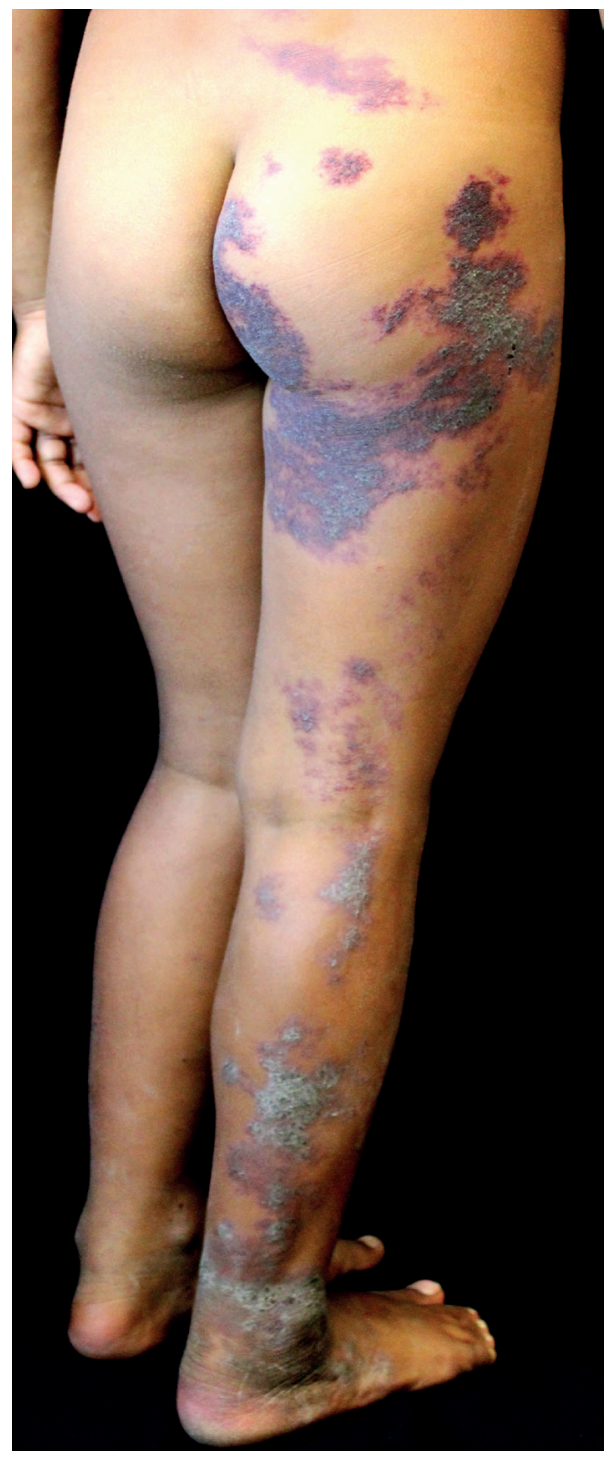

Figure 1: Extensive lesion with erythematous-violaceous squamous plaques with a linear pattern

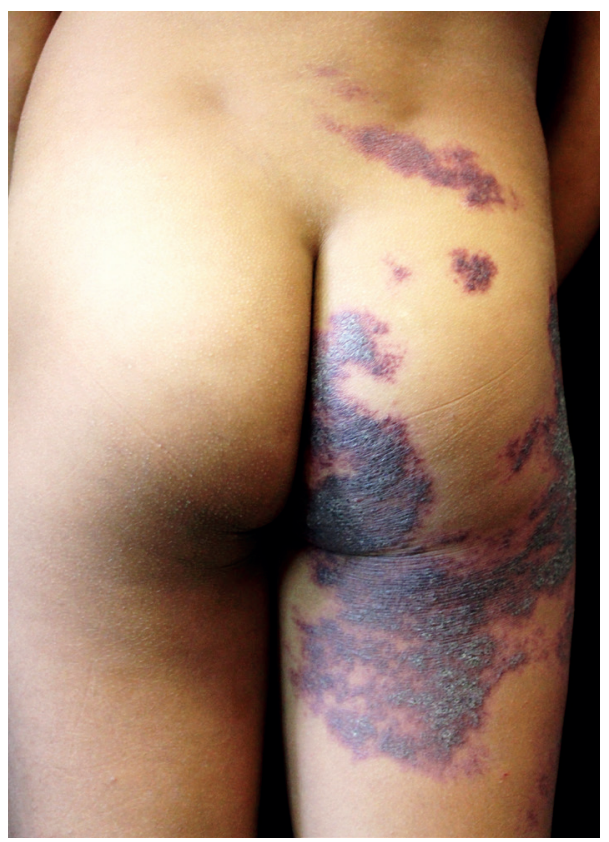
of erythematous-violaceous lesion on

lumbosacral and gluteal regions and posterior thigh
FIGURE 2: Detail

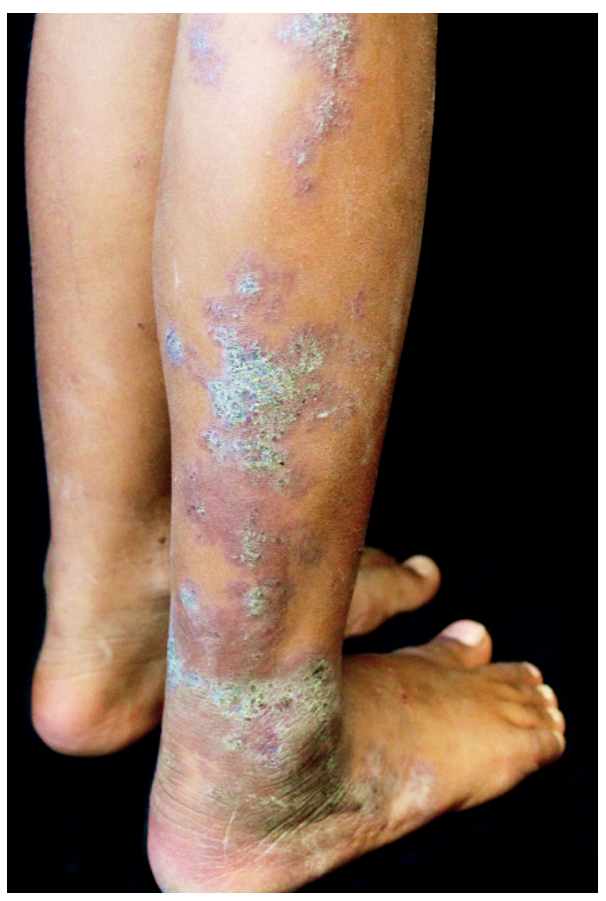

Figure 3: Detail of keratotic lesion on posterior leg

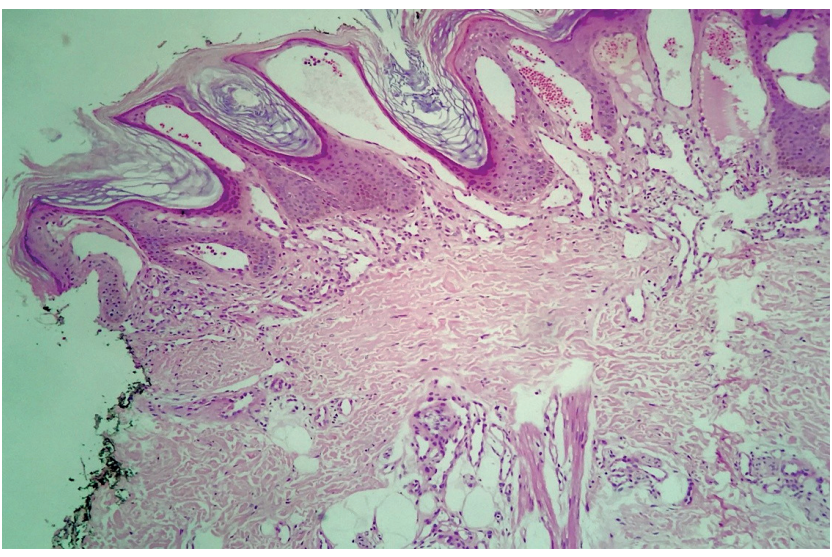

Figure 4: Overall appearance on histopathology. Mild hyperkeratosis and acanthosis; papillomatosis; vascular proliferation, predominantly in the papillary dermis (Hematoxylin \& eosin, x50)

extending to the subcutaneous tissue (Figures 4 and 5). Combined clinical and histopathological findings determined the diagnosis as verrucous hemangioma $(\mathrm{VH})$.

\section{DISCUSSION}

$\mathrm{VH}$ is a rare congenital vascular anomaly with a clinical presentation very similar to that of angiokeratoma circumstriptum neviforme (ACN). The International Society for the Study of Vascular Anomalies (ISSVA) stratifies vascular anomalies into vascular tumors and vascular malformations. Vascular tumors, such as in- 


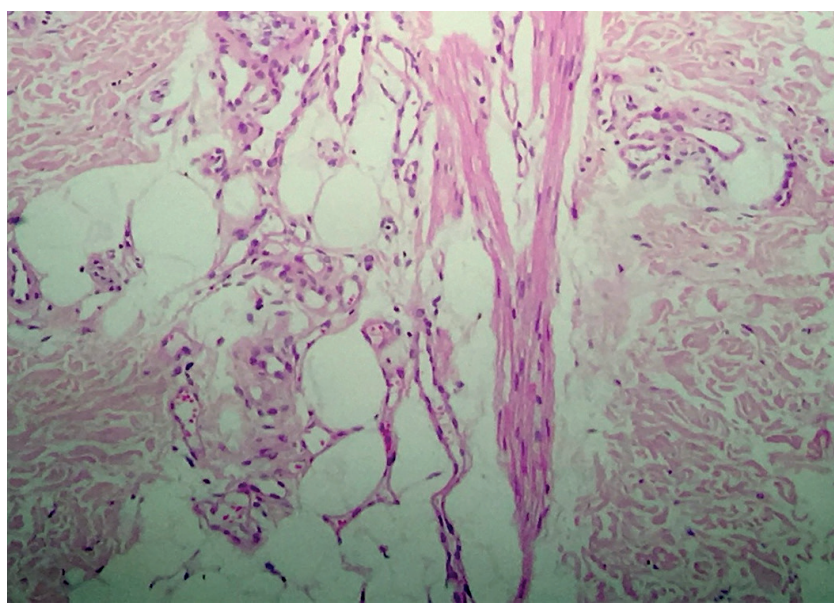

FIGURE 5: Fundamental detail on histopathology. Proliferation of small vessels also in the subcutaneous tissue, characteristic of verrucous hemangioma (Hematoxylin \& eosin, x200)

fantile hemangiomas, result from exacerbated cell proliferation, are more prevalent in females, tend to regress with the child's growth, and present positive immunohistochemistry for WT1 (Wilms tumor 1 protein) and GLUT1 (glucose transporter-1 protein). ${ }^{1}$ On the other hand, vascular malformations consist of errors in vessel morphogenesis, with equal male/female prevalence, that grow proportionally with the child, and that do not display involution or positive IHC for WT1 or GLUT1. ${ }^{1}$

Despite important efforts to standardize the nomenclature for vascular anomalies, the case reported here illustrates the difficulty in classifying these disorders. Some authors, like Imperial and Helwig, consider VH a malformation involving the subcutaneous tissue, with reactive acanthosis and epidermal hyperkeratosis; however, other authors consider it a true hemangioma (tumor), since its present positivity for WT1 and GLUT1. ${ }^{3}$ The ISSVA classification of 2014 includes $\mathrm{VH}$ - as well as its principal differential diagnosis, ACN - in the disorders yet not classified, since the clinical-pathological characteristics are still not totally clear. ${ }^{1}$

The clinical presentation of $\mathrm{VH}$ and $\mathrm{ACN}$ include erythematous patches that evolve to squamous and even verrucous plaques, most often affecting the lower limbs. ${ }^{4,5}$ Given the clinical similarity, anatomical pathological examination is imperative for diagnostic confirmation. In ACN the epidermal findings of acanthosis with hyperkeratosis - often even hypergranulosis - are very evident and

\begin{tabular}{|c|c|c|}
\hline & VH & $\mathrm{ACN}$ \\
\hline Age at onset & $\begin{array}{l}\text { At birth or in early } \\
\text { infancy }\end{array}$ & $\begin{array}{l}\text { At birth or in early } \\
\text { infancy }\end{array}$ \\
\hline Sex & $\begin{array}{l}\text { No predilection, or } \\
\text { male predominance? }\end{array}$ & Females (3:1) \\
\hline $\begin{array}{l}\text { Clinical } \\
\text { presentation }\end{array}$ & $\begin{array}{l}\text { Violaceous } \\
\text { hyperkeratotic } \\
\text { plaques on lower } \\
\text { limbs }\end{array}$ & $\begin{array}{l}\text { Violaceous } \\
\text { hyperkeratotic } \\
\text { plaques on lower } \\
\text { limbs }\end{array}$ \\
\hline Histopathology & $\begin{array}{l}\text { Involvement of the } \\
\text { subcutaneous tissue }\end{array}$ & $\begin{array}{l}\text { Involvement of the } \\
\text { papillary dermis }\end{array}$ \\
\hline $\mathrm{IHC}$ & $\begin{array}{l}\text { Positive to GLUT1 } \\
\text { and WT1 }\end{array}$ & $\begin{array}{l}\text { No reports of } \\
\text { positivity }\end{array}$ \\
\hline Evolution & $\begin{array}{l}\text { Progression } \\
\text { accompanies child's } \\
\text { growth }\end{array}$ & No reliable data \\
\hline Management & Laser (deeper) & $\begin{array}{l}\text { Cryotherapy, } \\
\text { electrocoagulation, } \\
\text { curettage, laser, } \\
\text { surgery }\end{array}$ \\
\hline
\end{tabular}

$\mathrm{VH}$ : verrucous hemangioma; ACN: angiokeratoma circumscriptum neviforme; IHC: immunohistochemistry

the vascular alterations are limited to the papillary dermis, whereas in $\mathrm{VH}$ the papillomatosis is a predominant feature, with vascular proliferation, and besides accompanying the papillomatosis in the papillary dermis, the vessels extend to the deep dermis and subcutaneous tissue. Chart 1 summarizes the differences between the two disease entities.

Another especially important complementary test is the scanogram, which measures the limbs comparatively. In the presence of asymmetry, Klippel-Trenaunay syndrome (KTS) should be remembered. The syndrome is characterized by the triad of Port wine stain, venous and lymphatic malformations, and hypertrophy of soft tissues in the affected area. There are some reports of association between $\mathrm{ACN}$ and KTS. ${ }^{5}$

Since $\mathrm{VH}$ lesions do not regress, but expand as the child grows, treatment becomes challenging. Combined therapy with surgery and laser is considered the first choice, and alternatives include cryotherapy and electrocoagulation. ${ }^{6}$ In more extensive cases, in which surgery becomes unfeasible, sirolimus can be an interesting option. ${ }^{7} \square$ 


\section{REFERENCES}

1. Wassef M, Blei F, Adams D, Alomari A, Baselga E, Berenstein A, et al. Vascular Anomalies Classification: Recommendations from the International Society for the Study of Vascular Anomalies. Pediatrics. 2015;136:e203-14.

2. Imperial R, Helwig EB. Verrucous hemangioma. A clinicopathologic study of 21 cases. Arch Dermatol. 1967:96:247-53

3. Knöpfel N, Hoeger PH. Hemangioma verrucoso o malformación venosa verrucosa? Hacia una clasificación asentada em el estudio genético. Actas Dermosifiliogr. 2016;107:427-8.

4. Ghosh SK, Bandyopadhyay D, Ghoshal L, Haldar S. Angiokeratoma circumscriptum naeviforme: A case report of a rare disease. Dermatol Online J. 2011;17:11
5. Wankhade V, Singh R, Sadhwani V, Kodate P, Disawal A. Angiokeratoma circumscriptum naeviforme with soft tissue hypertrophy and deep venous malformation: A variant of Klippel Trenaunay syndrome? Indian Dermatol Online J. 2014;5:S109-12.

6. Yang $\mathrm{CH}$, Ohara $\mathrm{K}$. Successful surgical treatment of verrucous hemangioma: a combined approach. Dermatol Surg. 2002;28:913-19.

7. Hammill AM, Wentzel M, Gupta A, Nelson S, Lucky A, Elluru R, et al. Sirolimus for the Treatment of Complicated Vascular Anomalies in Children. Pediatr Blood Cancer. 2011;57:1018-24.

\section{AUTHORS' CONTRIBUTIONS}

Kenselyn Oppermann

(iD) ORCID 0000-0003-0519-2868

Preparation and writing of the manuscript, Collecting, analysis and interpretation of data, Effective participation in research orientation, Critical review of the literature Ana Letícia Boff (iD) ORCID 0000-0002-5207-0567

Effective participation in research orientation
Renan Rangel Bonamigo ORCID 0000-0003-4792-8466

Approval of the final version of the manuscript, Effective participation in research orientation, Intellectual participation in propaedeutic and/or therapeutic conduct of studied cases, Critical review of the literature, Critical review of the manuscript

How to cite this article: Oppermann $\mathrm{K}$, Boff AL, Bonamigo RR. Verrucous hemangioma and histopathological differential diagnosis with angiokeratoma circumscriptum neviforme. An Bras Dermatol. 2018;93(5):712-5. 